\title{
Estratégias para melhorar a experiência de jogo do jogador idoso
}

\author{
Rômulo Batista da Silva ${ }^{1}$ \\ Lucila Ishitani $^{2}$
}

\begin{abstract}
Resumo: Os idosos, uma parcela da população que tem aumentado no decorrer dos anos, estão apresentando interesse crescente por jogos digitais. Entretanto, quase não existem jogos desenvolvidos para esse público. Este trabalho baseia-se na experiência de fluxo como fator significativo a ser considerado na criação de jogos dirigidos à terceira idade. Dessa forma, o objetivo é propor estratégias para melhorar a experiência do jogador idoso. Para cumprir o objetivo foi analisada a experiência de dois grupos de idosos durante a utilização de jogos digitais por meio de diários, entrevistas, observações e questionários, baseando a metodologia na abordagem de estudo de caso e usando a teoria fundamentada e técnicas estatísticas para as análises. Os resultados indicaram que a experiência de fluxo é importante para os jogadores idosos e permitiram identificar dois novos elementos considerados significativos, além de confirmar a importância da Teoria da Diversão para este público. As principais contribuições são possibilitar a criação de jogos voltados para a terceira idade capazes de aumentar qualitativamente e quantitativamente experiências como a diversão e o envolvimento, e permitir-lhes o contato com uma opção de lazer, aprendizado e de aproximação com a tecnologia.
\end{abstract}

Palavras-chave: Experiência de fluxo. Fluxo. Idosos. Jogos digitais. Terceira idade.

\begin{abstract}
The elderly, which is a group of people that has been worldwide growing over the years, have been showing interest in digital games, though there are hardly any games developed for them. This work is based on the flow of experience as a significant factor to be considered in creating games aimed at them. Thus, the goal is to propose strategies for enhancing the experience of the old player. In order to fulfill this objective we analyzed the experience of two groups of elderly people when using digital games, through diaries, interviews, observations and questionnaires, based on the case study methodology and by using grounded theory and statistical analysis. The results indicated that the flow experience is important for the older players, elicited two newly significant elements and found the importance of Fun Theory for this audience. The main contributions are to enable the design of games focused on old people and able to increase qualitatively and quantitatively experiences like fun and involvement, besides being an option for leisure, learning and promoting the use of technology.
\end{abstract}

Keywords: Digital games. Elderly. Flow. Flow experience. Seniors.

\section{Introdução}

O número de pessoas jogando jogos digitais são números muito significativos. Segundo a Entertainment Software Association (ESA) em seu relatório anual Essential Facts About the Computer and Video Game Industry (2014), 59\% dos americanos jogam videogames e de acordo com a UK Interactive Entertainment Association (UKIE) em seu relatório UK Video Games Fact Sheet, havian 1,6 bilhões de jogadores no mundo em 2013 [1].

Além disso, a área de jogos digitais está adquirindo maturidade como campo de pesquisa proporcionando diversos estudos dedicados à investigação de diferentes experiências [2]. Uma das finalidades é obter uma compreensão mais profunda de experiências subjetivas tais como imersão, presença e fluxo.

\footnotetext{
${ }^{1}$ Núcleo de Informática, IFNMG, Campus Teófilo Otoni - Rua Mocambi - 295 - Viriato - Teófilo Otoni (MG) - Brasil

\{romulo.silva@ifnmg.edu.br\}

${ }^{2}$ Programa de Pós-Graduação em Informática, PUC Minas, Campus São Gabriel - Rua Walter Ianni - 255 - Belo Horizonte (MG) - Brasil $\{$ lucila@pucminas.br $\}$
}

http://dx.doi.org/10.5335/rbca.v9i4.6777

Revista Brasileira de Computao Aplicada (ISSN 2176-6649), Passo Fundo, v. 9, n. 4, p. 120-135, dez. 2017120 
A ESA informou em seu relatório de 2007 que 24,2\% dos jogadores americanos possuíam idade igual ou superior a 50 anos [3]. Em 2011, esse percentual aumentou para 29\% [4]. De 2012 para 2013, nos Estados Unidos, o número de jogadores do sexo feminino com idade igual ou superior a 50 anos aumentou 32\% [5]. Esses dados indicam que a terceira idade tem apresentado interesse em jogos digitais.

Aliado a isso tem-se o aumento da expectativa de vida que gera um crescimento mundial no percentual de idosos. De acordo com o relatório World Population Prospects - The 2015 Revision elaborado pela Nações Unidas, em 2015, 901 milhões de pessoas eram idosas, ou seja, possuíam 60 anos ou mais. O número de idosos no mundo é projetado para ser de 1,4 bilhões em 2030, 2,1 bilhões em 2050, e pode subir para 3,2 bilhões em 2100 [6].

A experiência de fluxo é uma das experiências subjetivas estudada em relação a jogos digitais. Fluxo (flow, no original em inglês), ou experiência ótima, é um conceito que se originou na psicologia e expressa o sentimento que as pessoas manifestam quando agem com total envolvimento [7].

Apesar dos dados apresentados indicarem que o número de idosos que utilizam jogos digitais está aumentando, são poucos os resultados encontrados na literatura sobre jogos desenvolvidos para as necessidades ou comportamento deste público. Melhorar a experiência de jogo dos jogadores idosos é analisada como uma contribuição importante porque pode permitir a criação de jogos mais compatíveis com seus interesses e possibilitar uma opção de lazer, entretenimento e aprendizado para esses indivíduos. A experiência de fluxo pode ser um fator relevante nessa tarefa.

O objetivo deste trabalho é propor estratégias para melhorar a experiência do jogador idoso. A finalidade é desenvolver jogos mais condizentes com os anseios da terceira idade e capazes de atrair mais a sua atenção e interesse.

Para a realização do trabalho proposto utilizou-se uma abordagem de pesquisa mista conferindo maior ênfase na parte qualitativa. Para a execução da parte qualitativa optou-se por utilizar o método de Estudo de Caso e usar a Teoria Fundamentada (Grounded Theory, no original em inglês) para a análise dos dados. A análise quantitativa foi feita por meio de técnicas estatísticas.

Os resultados indicaram que os elementos do fluxo são fatores significativos para o idoso ter uma melhor experiência com jogos digitais, além disso determinou a importância de dois elementos, a motivação e o gostar de jogar, que foram as categorias centrais da teoria desenvolvida.

A próxima seção apresenta o referencial teórico no qual essa pesquisa se baseia. Na seção 3 é descrita a metodologia utilizada para o desenvolvimento da pesquisa. A seção 4 apresenta os resultados obtidos. E na seção 5 são discutidas as considerações e conclusões da pesquisa.

\section{Fluxo e Teoria da Diversão}

A Teoria do Fluxo [7] foi desenvolvida por Mihaly Csikszentmihalyi, psicólogo contemporâneo que realizou uma extensa pesquisa sobre motivação, felicidade e criatividade.

Para que ocorra a experiência de fluxo é necessário que exista equilíbrio entre o desafio da tarefa que está sendo realizada e as habilidades daquele que a executa. Caso o desafio seja maior que as habilidades, o indivíduo entra em estado de ansiedade e, caso contrário, ou seja, as habilidades superiores ao desafio, o estado provocado é o de tédio. Ambos os casos geram descontentamento ou desprazer com a tarefa. É importante destacar que a existência do equilíbrio entre as habilidades e os desafios não determina a ocorrência do fluxo, mas este equilíbrio é o elemento principal.

Além disso, é necessário que os objetivos da tarefa sejam claros e forneçam respostas imediatas para que a pessoa não tenha dúvidas ao realizá-los. Quando uma pessoa está em estado de fluxo ela se concentra completamente na atividade que está realizando. Isso acarreta a perda da noção de tempo e da autoconsciência.

A Teoria do Fluxo consiste de nove elementos fundamentais [7]: desafio, habilidades, objetivos claros, feedback, concentração, percepção de tempo alterada, perda da autoconsciência, controle e experiência autotélica.

A experiência autotélica é o objetivo final do estado de fluxo porque a pessoa envolve-se novamente na tarefa pelo fato de ser intrinsecamente motivador e prazeroso realizá-la, ou seja, a recompensa da tarefa é sua

Revista Brasileira de Computao Aplicada (ISSN 2176-6649), Passo Fundo, v. 9, n. 4, p. 120-135, dez. 2017121 
própria realização.

Por sua vez, a Teoria da Diversão [8] foi desenvolvida por Raph Koster, projetista de jogos que utilizou sua experiência para elaborar uma visão de jogos por meio da diversão e da aprendizagem. Segundo Koster [8], quando o cérebro pratica alguma coisa, ele está trabalhando para transformar padrões recém-apreendidos em algo que se encaixe no contexto de tudo o mais que as pessoas sabem. O objetivo final é tornar tal coisa uma rotina. Os jogos são uma ferramenta útil para isso porque no mundo real existem diversos sistemas que podem ser abordados como jogos, por exemplo, aprender a tocar um instrumento musical ou a dirigir, com riscos muito menores.

Entretanto quando não existem novos padrões para o cérebro absorver, o sentimento que surge é o tédio. "O tédio é o oposto de aprendizagem" [8], quando um jogo deixa de ensinar, os jogadores se sentem aborrecidos e o cérebro procura novas informações em outras coisas. O cérebro anseia por estímulos buscando aprender alguma coisa ou tentando integrar informações.

Percebe-se que em ambas as teorias o equilíbrio entre os desafios e as habilidades do jogador é um fator muito importante para alcançar sentimentos prazerosos e envolver-se com o jogo. Apesar dessa importância, raros são os estudos que analisam a aplicação dessas teorias em jogos para idosos [9].

As preferências de 66 jogadores idosos (55 a 88 anos) foram analisadas e, dentre outros resultados, foi possível identificar que competir contra um parceiro de habilidade semelhante foi mais agradável do que o esperado [10]. Wang et al. [11] compararam dois métodos de balanceamento de atividades (Manual Difficulty Adjustment - MDA e Dynamic Difficulty Adjustment - DDA) e concluíram que o MDA tem maior impacto na experiência do jogador idoso. Lins et al. [12] acompanharam o uso de um aplicativo por 82 participantes (63 a 96 anos), durante dois anos. Dentre os resultados de seu estudo, os autores concluíram que desenvolvedores de aplicativos para idosos devem considerar o conceito de fluxo e que há necessidade de mais pesquisas na área.

Em geral, os estudos encontrados tiveram como foco a avaliação de um jogo desenvolvido com foco no público da terceira idade. Por exemplo, a experiência de fluxo utilizando o exergame iStopFalls foi avaliada por 95 participantes (65 a 92 anos) [9] e a experiência de 6 usuários idosos (média de 82 anos) foi avaliada utilizando jogos para reabilitação de memória [13]. Assim, percebe-se a necessidade de mais estudos que proponham estratégias para melhoria da experiência do jogador idoso, extrapolando o foco na avaliação da experiência. Nessa linha de pesquisa, foi encontrado um único trabalho [14] que teve por objetivo propor estratégias de design para aplicativos para adultos mais velhos, mas com um foco muito específico em atividades físicas.

\section{Metodologia}

Nesta seção apresenta-se a metodologia de pesquisa utilizada para a realização do trabalho.

Para cumprir os objetivos da pesquisa inicialmente foi estudada a Teoria do Fluxo e em seguida realizada uma revisão sistemática da literatura buscando por pesquisas envolvendo o fluxo em jogos digitais e como ele pode ser mensurado. $\mathrm{O}$ objetivo desta etapa era entender melhor o fluxo, verificar a adequação das questões de pesquisa e refinar os objetivos do trabalho.

Ao final desta etapa decidiu-se por utilizar uma abordagem de pesquisa mista, mas conferindo maior ênfase na parte qualitativa pelo fato de existirem poucos estudos sobre o fluxo, em jogos digitais, relacionado à terceira idade. Para promover a execução da parte qualitativa dentro dos moldes deste tipo de pesquisa optou-se por delinear o trabalho por meio de um Estudo de Caso e utilizar a Teoria Fundamentada para a análise dos dados. O planejamento das demais etapas foi realizado tendo esta abordagem como premissa.

\subsection{Planejamento do estudo de caso}

De acordo com Yin [15], "como método de pesquisa, o estudo de caso é usado em muitas situações, para contribuir ao nosso conhecimento dos fenômenos individuais, grupais, organizacionais, sociais, políticos e relacionados". Para o planejamento do estudo de caso a definição do caso e da unidade de análise é de fundamental importância. Yin [15] argumenta que um projeto de estudo de caso pode ser holístico (possui uma única unidade de análise) ou integrado (possui múltiplas unidades de análise) e pode ser composto por apenas um caso (caso único) ou por vários casos (casos múltiplos).

Revista Brasileira de Computao Aplicada (ISSN 2176-6649), Passo Fundo, v. 9, n. 4, p. 120-135, dez. 2017122 
As quatros principais formas de projetos surgem da combinação destes tipos: Projeto de caso único holístico, Projeto de caso único integrado, Projeto de casos múltiplos holístico, e Projeto de casos múltiplos integrado.

A partir destes tipos de projeto, este trabalho foi definido como um estudo de casos múltiplos holístico. Holístico porque a unidade de análise é a experiência de fluxo em jogos digitais, pois o objetivo do trabalho era verificar o efeito do fluxo sobre jogadores da terceira idade e como melhorar essa experiência. Casos múltiplos porque desejava-se verificar se a experiência de fluxo em relação a jogos digitais apresentava diferenças devido ao maior ou menor contato com a tecnologia. Decidiu-se dividir os participantes em dois grupos, desta forma, cada grupo é um caso representativo para esta investigação.

\subsection{Seleção dos jogos}

Para a seleção dos jogos foram utilizados critérios com base nos trabalhos de Carvalho e Ishitani [16], Santos [17], Cota [18] e Machado [19]. O trabalho de Carvalho e Ishitani [16] apresentou os fatores motivacionais capazes de influenciar a terceira idade a utilizar os jogos digitais. O trabalho de Santos [17] forneceu as heurísticas de usabilidade que os jogos deveriam apresentar para serem adequados para o público da terceira idade, o trabalho de Cota [18] informou quais as principais categorias de jogos que este público prefere jogar e o trabalho de Machado [19] apresentou as heurísticas de gameplay necessárias para o desenvolvimento de jogos para os idosos.

Tendo como base estes trabalhos foi desenvolvido o jogo "Viajando pelo Mundo" [20]. Este jogo foi desenvolvido com foco em idosos e foi avaliado nos trabalhos de Santos [17], Cota [18] e Machado [19], por isso foi um dos jogos selecionados.

Figura 1: Imagens do jogo Viajando pelo Mundo
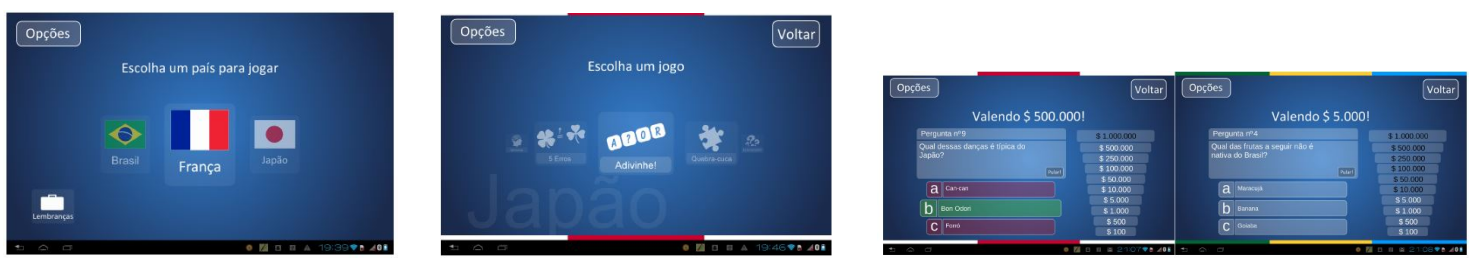

No trabalho de Machado [19], além do "Viajando pelo Mundo" foram avaliados alguns jogos comerciais disponíveis na PlayStore ${ }^{3}$, entre eles estava o "Cut the Rope $e^{4 "}$ que apresentou a melhor média de avaliação pelos especialistas e pelos participantes e, assim, também foi selecionado.

Com base no trabalho de Cota [18] foram selecionados dois jogos que pertenciam a cada uma das categorias de jogos preferidas pelos idosos. O local para a busca dos jogos foi a PlayStore. Estes jogos foram avaliados com base nas heurísticas de usabilidade para idosos. O jogo com a melhor avaliação foi selecionado para os testes. Este jogo foi o "Dots".

Figura 2: Imagens do jogo Cut the Rope
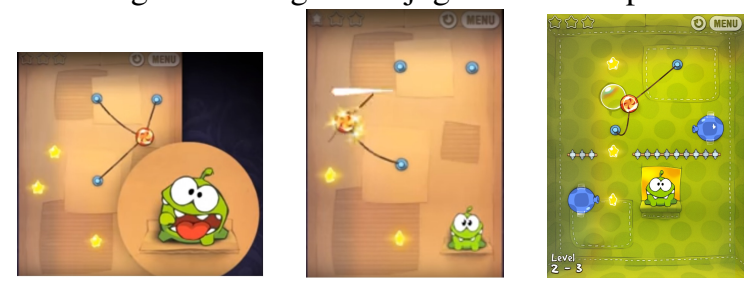

Figura 3: Imagens do jogo Dots

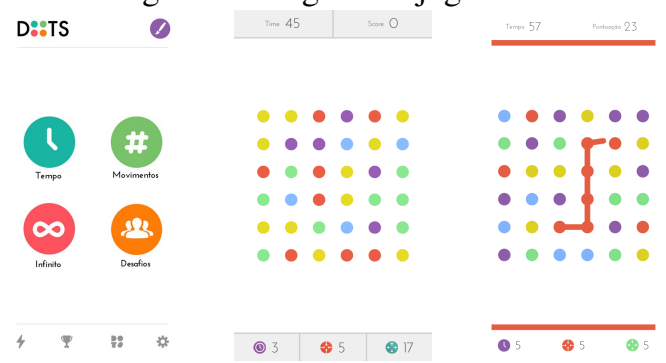

${ }^{3}\langle$ https://play.google.com/store $\rangle$

${ }^{4}$ 〈www.cuttherope.net

${ }^{5}\langle\mathrm{http}: / /$ weplaydots.com/ $\rangle$ 
Dessa forma, foram selecionados três jogos. A razão para isso é devido ao fato dos testes terem uma duração longa, dois meses, e a utilização de apenas um jogo neste período poderia se tornar monótona. Além disso, desejava-se avaliar o fluxo em diferentes jogos para verificar se esta experiência poderia mudar de acordo com o jogo utilizado.

\subsection{Seleção dos participantes}

Os dois principais critérios para a seleção dos participantes foram: ter no mínimo 60 anos de idade e não possuir alguma deficiência cognitiva que impossibilitasse a participação nos testes. Outro critério utilizado foi quanto ao uso da tecnologia, porque se desejava verificar se a experiência de fluxo em relação a jogos digitais apresentava diferenças devido ao maior ou menor contato com a tecnologia.

Para verificar a adequação aos critérios de seleção foram utilizados dois instrumentos: questionário demográfico e Mini Exame do Estado Mental (MEEM) [21]. O questionário demográfico tinha por objetivos determinar o grupo no qual o participante seria integrado. O MEEM foi usado para medir o nível de deficiência cognitiva do participante.

Oito participantes foram selecionados, a média de idade foi de 65,5 anos variando entre 60 a 74 anos. No trabalho realizado por Singh e Malhotra [22], as autoras afirmam que o número usual de participantes em estudos envolvendo diários é entre oito a dez.

Os participantes foram divididos em dois grupos de pesquisa: Grupo 1 - Menor uso da tecnologia: composto por quatro participantes; Grupo 2 - Maior uso da tecnologia: composto por quatro participantes.

Os participantes utilizaram um smartphone para sessões de jogo no período de dois meses. Os smartphones utilizados pertencem ao grupo de pesquisa Informática na Educação, o modelo do dispositivo é Nexus 4, fabricado pela LG, com as seguintes especificações: Android 4.2, processador quad-core $1.5 \mathrm{GHz}$, tela de 4.7 polegadas e memória de 16 GB.

A utilização de smartphones no estudo deve-se a motivos relevantes: segundo o Global Games Market Report (2017), jogos para dispositivos móveis dominam o mercado mundial de games [23]; são mais populares e mais acessíveis financeiramente do que os para notebooks ou computadores; e os celulares, geralmente, já são utilizados pelos idosos.

O período de testes foi dividido em quatro fases com duração de 15 dias cada uma. Durante as três primeiras fases cada participante deveria jogar um único jogo definido de maneira aleatória. Na última fase os participantes tinham os três jogos a disposição e poderiam jogar da forma que desejassem. O número de sessões, o horário e a duração de cada sessão esteve a cargo do participante, mas era recomendado que os participantes jogassem pelo menos três vezes na semana.

\subsection{Procedimentos de coleta de dados}

Em uma pesquisa qualitativa existem diferentes fontes de dados que podem ser utilizadas para se obter evidências [24, 25]. As fontes para a coleta de dados foram os diários e as entrevistas. Durante esta etapa utilizouse a pesquisa in loco, ou seja, os participantes foram entrevistados em seus respectivos contextos.

Por se tratar de uma pesquisa mista a parte quantitativa foi realizada utilizando uma versão adaptada da Escala de Fluxo (Flow Escale) [26]. Nesta versão a escala foi traduzida para o português e alguns itens foram adequados tendo em vista o público alvo, assim procurou-se simplificar o máximo possível os itens para melhorar o entendimento dos respondentes. Além disso, ela passou a ser uma escala Likert de cinco pontos.

As atividades realizadas durante a coleta de dados foram:

\section{Atividade 1 - Questionário demográfico e MEEM}

Inicialmente os participantes responderam o questionário com informações demográficas e o MEEM. As respostas foram utilizadas para verificar a adequação aos critérios de seleção dos participantes e também para determinar o grupo no qual o participante seria alocado.

Revista Brasileira de Computao Aplicada (ISSN 2176-6649), Passo Fundo, v. 9, n. 4, p. 120-135, dez. 2017124 
O MEEM classifica como condição cognitiva normal uma pontuação igual ou superior a 25 , de um total de 30. Os resultados dos participantes variaram entre 25 e 29 pontos, sendo assim todos foram considerados aptos a participarem dos testes.

\section{Atividade 2 - Estudos diários}

Segundo Mekler et al. [27], estudos diários aplicados em jogos podem fornecer informações sobre como as emoções e os pensamentos dos jogadores se modificam ao longo do tempo e podem ajudar a identificar o que os jogadores anseiam experimentar em sua próxima sessão de jogo.

Os diários tinham como objetivos coletar informações como: data da sessão de jogo; horário de início e de término da sessão de jogo; e percepções sobre o jogo como, por exemplo, primeira impressão, o que mais/menos gostou, se foi divertido ou não, se a primeira impressão mudou no decorrer do período.

Optou-se pela utilização de diários no formato de caderno brochura, a razão para esta escolha foi pelo fato de um dos grupos previstos para a pesquisa possuir pouco contato com a tecnologia. O uso de um diário digital poderia ser um elemento dificultador e desmotivador para estes participantes.

Ao contrário de questionários e entrevistas, os diários exigem maior esforço por parte dos participantes. Por esta razão é possível que apresente limitações como o não preenchimento de forma devida pelos participantes. Dearman, Kellar e Truong [28] sugerem algumas estratégias para minimizar estas limitações.

\section{Atividade 3 - Entrevistas}

De acordo com Yin [15] as entrevistas são muito importantes como fontes de evidências em estudos de caso. Flick [24], classifica as entrevistas como: entrevista focalizada, entrevista semipadronizada ou semiestruturada, entrevista centrada no problema e entrevista etnográfica. Nesta pesquisa, utilizou-se a entrevista semiestruturada para permitir ao pesquisador inserir ou modificar perguntas de acordo com as respostas do participante.

Para este trabalho foi elaborado um roteiro de entrevista que se concentrava nos noves elementos fundamentais do fluxo [7], porque o objetivo era verificar se essa experiência ocorria nos membros da terceira idade da mesma forma encontrada na literatura e como ela poderia ser melhorada em jogos digitais desenvolvidos para eles.

Foram realizadas quatro entrevistas com cada participante, uma ao final de cada fase das sessões de jogos (quinze dias). O tempo total das entrevistas foi superior a 09:30 (nove horas e trinta minutos), resultando em um tempo médio de aproximadamente 18 minutos. Todas as entrevistas foram transcritas para as análises.

\section{Atividade 4 - Escala de Fluxo}

A Escala de Fluxo, desenvolvida por Kiili e Lainema [26], é um instrumento para mensurar o fluxo em jogos digitais. Esta escala foi utilizada inicialmente com adolescentes e depois com estudantes universitários. A razão para a escolha deste instrumento para mensurar o fluxo foi devido ao número de questões que este continha, nove no total, porque acreditava-se que um instrumento muito extenso poderia ser inapropriado para o público da terceira idade. Além disso, é um instrumento já utilizado em alguns trabalhos encontrados na literatura Kiili et al. [29], Kara e Cagiltay [30] e Kiili et al. [31].

Os objetivos de utilizar este instrumento eram para a análise estatística e para fins de triangulação dos dados, uma vez que as respostas da entrevistas e relatos nos diários poderiam ser confrontados com as respostas deste questionário.

\subsection{Procedimentos de análise dos dados}

Uma das formas para a utilização da pesquisa qualitativa e quantitativa em conjunto, e que foi aplicada neste trabalho, é a lógica da triangulação [32] que consiste na comparação dos resultados qualitativos com os resultados quantitativos.

Para realizar as análises das entrevistas e dos diários foi utilizada a Teoria Fundamentada. O método foi adaptado do proposto por Charmaz [33].

A Escala de Fluxo foi analisada por meio de estatística descritiva e inferencial. Por possuir dados nãoparamétricos, uma vez que é uma escala ordinal, foi utilizado um teste para dados classificados [34]. O teste

Revista Brasileira de Computao Aplicada (ISSN 2176-6649), Passo Fundo, v. 9, n. 4, p. 120-135, dez. 2017125 
definido foi o de Wilcoxon-Mann-Whitney.

\subsection{Teoria Fundamentada}

A Teoria Fundamentada (Grounded Theory, no original em inglês) é uma metodologia focada na concepção e aperfeiçoamento de teorias que caracterizam um fenômeno e as condições para sua ocorrência. Foi desenvolvida pelos sociólogos Barney Glaser e Anselm Strauss.

A análise na Teoria Fundamentada concentra-se na interpretação dos dados que é "a essência da pesquisa qualitativa" [24]. Para isto utiliza o procedimento de codificação. De acordo com Charmaz [33], "a codificação é o elo fundamental entre a coleta dos dados e o desenvolvimento de uma teoria emergente para explicar esses dados". Os códigos surgem da análise cuidadosa dos dados e definem significados para eles.

Neste trabalho, a codificação foi realizada por meio do método proposto por Charmaz [33] e se divide em:

\section{Codificação inicial}

Charmaz [33] descreve três possibilidades para a codificação inicial: codificação palavra por palavra, codificação linha a linha e codificação incidente por incidente.

Optou-se por usar a codificação linha a linha que consiste em denominar cada linha dos dados. Essa denominação pode ser por meio da principal ideia contida na linha ou pelos códigos in vivo que são termos específicos usados pelos próprios participantes.

\section{Codificação focalizada}

Na codificação focalizada são utilizados os códigos mais significativos e/ou frequentes da codificação inicial para analisar um conjunto maior de dados. O objetivo é "sintetizar e explicar segmentos maiores de dados" [33, p. 87].

\section{Codificação axial}

Relaciona as categorias resultantes da codificação focalizada às suas subcategorias. O objetivo é especificar as propriedades e dimensões de uma categoria, e reagrupar os dados fragmentados. A codificação axial visa a responder questões como "quem, "quando", "por que", "onde", "como" e "com que consequências", fornecendo uma estrutura que pode ser aplicada na pesquisa.

\section{Codificação teórica}

A codificação teórica caracteriza as possíveis relações entre as categorias desenvolvidas. Segundo Charmaz [33], "é um nível sofisticado de codificação" no qual os códigos teóricos são "integrativos" ao entrelaçarem os códigos focais.

\section{Resultados}

No trabalho optou-se por fazer a análise qualitativa primeiro. Glaser e Strauss [35] e Charmaz [33] recomendam que as análises dos dados na Teoria Fundamentada iniciem antes de terminada a coleta porque os achados significantes podem ser verificados com os demais participantes da pesquisa ou direcionar a escolha de novos participantes. Dessa forma, ao se obter uma parte das entrevistas iniciou-se o processo de análise. Após a realização da análise qualitativa foi feita a análise quantitativa.

Os participantes da pesquisa foram divididos em dois grupos de acordo com o grau de utilização da tecnologia e cada grupo era composto por quatro participantes. O Grupo 1 - Menor uso da tecnologia era formado por Ana, Getúlio, João e Marta. O Grupo 2 - Maior uso da tecnologia tinha como integrantes André, Beatriz, Helena e Izabela. Os nomes dos participantes da pesquisa, bem como outros que aparecem em suas falas foram alterados para preservar sua privacidade.

Nesta pesquisa tomou-se como hipótese: a experiência de fluxo não apresenta diferença significativa entre os grupos.

Revista Brasileira de Computao Aplicada (ISSN 2176-6649), Passo Fundo, v. 9, n. 4, p. 120-135, dez. 2017126 


\subsection{Resultados da análise qualitativa}

Para a transcrição das entrevistas foi utilizado o programa "Listen $N$ Write Free". As análises das entrevistas e dos diários foram efetuadas utilizando o " $R Q D A$ ", que é um pacote desenvolvido na linguagem " $R$ " para análise de dados qualitativos.

O método para análise de dados utilizando a Teoria Fundamentada proposto por Charmaz [33] foi adaptado para este trabalho. Embora existisse a separação dos participantes em dois grupos, durante as análises da Teoria Fundamentada não foi feita tal separação porque, como foi dito, os achados importantes poderiam ser verificados com os outros participantes independente do grupo. Dessa forma, seria possível verificar com maior certeza se a diferença em relação ao contato com a tecnologia teria influência sobre o fluxo dos jogadores.

O resultado obtido em cada uma das etapas é descrito a seguir:

Codificação inicial - Ao final da codificação inicial foram obtidos mais de 300 códigos.

Codificação focalizada - Após a codificação focalizada, os códigos foram reduzidos para 115.

Codificação axial - A codificação axial teve como resultado 23 categorias.

Codificação teórica - A codificação teórica produziu 15 relações. Algumas destas relações serão apresentadas e discutidas no decorrer desta seção.

\subsubsection{Relações identificadas}

Relação III: Experiência autotélica tem efeito sobre a Motivação, o Gostando de jogar, a Percepção de tempo alterada e a Perda da autoconsciência

Segundo Csikszentmihalyi [7], a experiência autotélica é o objetivo final do estado de fluxo porque a pessoa sente prazer em realizar a tarefa (no caso da pesquisa, em jogar) e por causa disso envolve-se novamente com ela. Dessa forma, a categoria Experiência autotélica afeta positivamente as categorias Motivação e Gostando de jogar como pode ser verificado no trecho a seguir:

Divertido muito prazerosa eu tô até com a ideia de comprar até falei "Karina (filha) eu tenho que comprar um celular agora pra eu poder jogar" (risos) porque eu nunca tinha jogado nada na minha vida nem no computador (né?). [Izabela]

Relação IV: Gostando de jogar afeta a Motivação, a Percepção de tempo alterada, a Perda da autoconsciência, o Lazer, a Concentração, as Habilidades e as Lembranças

Pelo fato de estar se divertindo o jogador se sente mais motivado a continuar jogando e por isso é capaz de desenvolver habilidades, como pode ser percebido no trecho a seguir:

(...) eu estou fazendo as outras coisas pensando "vou terminar rapidinho pra mim poder jogar" (né?)(...) agora é bom porque eu acho que está contribuindo pra minha concentração (...) eu notei assim um pouquinho diferente nesses dias (...) quinze dias bem pouco (né?)(...) mas já fez diferença. [Helena]

Relação IX: Motivação tem efeito sobre o Gostando de jogar, o Lazer, a Experiência autotélica, as Habilidades, a Concentração, a Percepção de tempo alterada e a Perda da autoconsciência

Por se sentir mais motivado, o jogador se concentra no jogo e, assim, não percebe os acontecimentos ao seu redor. $\mathrm{O}$ trecho a seguir expõe tal fato:

Porque eu fico muito concentrado fico querendo fazer mais pontos (...) fica naquela ansiedade e aí eu (...) esqueço das coisas. [João] 


\section{Relação XII: Equilíbrio entre desafios e habilidades tem efeito sobre a Motivação, a Desmotivação e o Gostando de jogar}

De acordo com Csikszentmihalyi [7], para a ocorrência do fluxo, o equilíbrio entre as habilidades e desafios é fundamental. Na percepção de sete dos participantes, a existência deste equilíbrio pode motivá-los ou desmotiválos e ainda fazer com que eles gostem do jogo. No trecho a seguir esta relação pode ser observada:

Quando ele está em equilíbrio (...)(uai!) porque fácil é fácil demais (risos)(...) aí quando é(...) difícil aí é que ele pode até trazer assim é raiva assim (sabe?) "ah que eu não aprendo que eu não sei o quê" (...) então assim eu acho que se for equilibrado você vai ter momentos pra você xingar porque você não consegue (risos)(...) mas você vai ter momentos que você vai fazer agora você põe um difícil aí eu nunca que eu faço aquilo (...) acaba desmotivando (frisando)(...) tem que ser uma coisa equilibrada. [Marta]

As demais relações identificadas foram:

- Relação I: Desafios têm efeito sobre a Motivação, a Desmotivação, o Gostando de jogar, a Percepção de tempo alterada, a Perda da autoconsciência e a Experiência autotélica.

- Relação II: Concentração no jogo afeta a Percepção de tempo alterada, o Gostando de jogar, as Habilidades e a Perda da autoconsciência.

- Relação V: Controle tem efeito sobre a Motivação, o Gostando de jogar e as Habilidades.

- Relação VI: Competição afeta a Interação social, o Gostando de jogar e a Percepção de tempo alterada.

- Relação VII: Habilidades tem efeito sobre a Percepção de tempo alterada, o Gostando de jogar, a Concentração, a Perda da autoconsciência e a Motivação.

- Relação VIII: Maior interação com jogos afeta a Motivação e o Gostando de jogar.

- Relação X: Não gostando de jogar afeta a Desmotivação.

- Relação XI: Perda da autoconsciência tem efeito sobre a Percepção de tempo alterada e vice-versa.

- Relação XIII: Aprendizado afeta o Gostando de jogar, o Diminuindo o medo da tecnologia e as Lembranças.

- Relação XIV: Objetivos claros tem efeito sobre o Gostando de jogar e a Motivação

- Relação XV: Feedback afeta a Motivação e a Desmotivação

\subsubsection{Percepções acerca do contato com jogos e a tecnologia}

Além das percepções relacionadas ao fluxo, os participantes também relataram sobre o pouco contato com jogos digitais ao longo de suas vidas, sobre diminuir o medo da tecnologia devido ao contato com os jogos e o smartphone, a melhoria na qualidade de vida que os jogos podem possibilitar, o aprendizado durante as sessões de jogo, a interação social que os jogos possibilitam e o jogo como uma opção de lazer. Alguns destes relatos serão apresentados a seguir.

\section{Diminuindo o medo da tecnologia}

O contato que os participantes tiveram com os jogos durante a execução dos testes, período de dois meses, foi considerado, por alguns, importante para diminuírem um pouco o medo que tinham da tecnologia e se sentirem mais confiantes na utilização do smartphone e em jogar. Mesmo aqueles que possuíam maior contato com a tecnologia, pelo fato de trabalharem muitos anos de suas vidas utilizando o computador em suas funções, perceberam esse efeito. No trecho a seguir pode ser verificada essa ocorrência:

Você lembra que eu falei que eu só fazia (jogava) aqui nesse cantinho (?) depois eu já ficava sentada na cama e tal (sabe?)(...) eu perdi o medo assim (risos)(...). [Izabela] 


\section{Melhoria na qualidade de vida}

Alguns participantes perceberam que os jogos possuem a capacidade de auxiliar no combate de doenças cognitivas e de promover melhorias na qualidade de vida. No trecho a seguir essas percepções podem ser verificadas:

\section{(...) desenvolver a cabeça em qualquer coisa é bom (...) evitar o Alzheimer (risos) coisa que eu acho que eu não vou ter fácil (...). [Beatriz]}

\subsection{Resultados da análise quantitativa}

É importante ressaltar que a presente análise estatística foi utilizada para a triangulação dos dados da análise qualitativa, não tendo a pretensão de ser usada como estatística inferencial, devido ao fato do número total de participantes ser oito, sendo considerado uma amostra não representativa da população em estudo.

Pelo fato da Escala de Fluxo ser do tipo Likert, ela é uma escala ordinal. Assim, os seus itens possuem uma relação de ordem e podem ser estabelecidas comparações como Concordo parcialmente é menor que Concordo plenamente.

Segundo Viali [37], "a estatística mais adequada para a descrição da tendência central dos valores em uma escala ordinal é a mediana”. Seguindo esta recomendação foram calculadas as medianas em cada jogo independente do grupo e depois dependente do grupo. Como os dados são classificados, o cálculo da mediana foi feito por meio da função cumulativa de frequências relativas, que é dado, pela fórmula:

$$
\frac{\Sigma f_{i}}{2}
$$

A menor frequência acumulada que supera o valor encontrado na fórmula corresponde ao valor mediano.

Os valores obtidos são apresentados na Tabelas 1 e 2 .

Tabela 1: Valor da mediana para os jogos

\begin{tabular}{|c|c|}
\hline Jogo & Mediana \\
\hline Dots & 5 \\
Cut the Rope & 5 \\
Viajando pelo Mundo & 5 \\
\hline
\end{tabular}

Tabela 2: Valor da mediana para os grupos

\begin{tabular}{|c|c|c|c|}
\hline Grupo & Dots & Cut the Rope & Viajando pelo Mundo \\
\hline Menor uso da tecnologia & 5 & 5 & 5 \\
Maior uso da tecnologia & 5 & 5 & 5 \\
\hline
\end{tabular}

Como pode ser observado, a mediana foi igual a cinco para todos os casos. Isto se deve ao fato deste valor ser o mais frequente nas respostas dos participantes. Das 216 respostas, somando todas as respostas dos participantes, o valor cinco ocorreu 117 vezes. Como este valor é o máximo na Escala de Fluxo, acredita-se que os participantes experimentaram o fluxo.

Para verificar a hipótese de que não haveria diferença significativa no fluxo entre os grupos, utilizou-se um teste não-paramétrico. Este tipo de teste é isento de premissas de distribuição [34] e pode ser usado com amostras pequenas. A razão para utilizar um teste não-paramétrico é porque os dados na Escala de Fluxo são classificados.

O teste selecionado foi o Wilcoxon-Mann-Whitney, ou teste $U$. A razão para a escolha deste teste foi porque ele foi desenvolvido, inicialmente, para comparar tendências centrais de duas amostras independentes e de tamanhos iguais, que é o mesmo caso dos grupos deste trabalho. 
Para amostras pequenas (nenhum n maior que 20) são fornecidos valores críticos de $U$ para os níveis de significância [37].

Para a execução do teste Wilcoxon-Mann-Whitney foi utilizado o "Action", um plugin para o Microsoft Excel que possui a capacidade de realizar diversos testes estatísticos.

Para todos os testes as hipóteses foram:

$$
\begin{gathered}
H_{0}=\text { o fluxo entre o grupos seria igual } \\
H_{A}=o \text { fluxo seria diferente entre os grupos }
\end{gathered}
$$

Realizou-se o teste para os jogos, nos três testes o intervalo de confiança foi de $95 \%$. O resultado obtido para os jogos Dots, Cut the Rope e Viajando pelo Mundo $(U=4$ e $P$-valor $=0,126630458 ; U=6$ e $P$-valor $=$ 0,$535703242 ; U=8$ e $P$-valor $=1$ respectivamente), indicaram que a hipótese nula não deve ser rejeitada. Assim, não existem evidências de que o maior ou menor contato com a tecnologia influencia a experiência de fluxo.

Nos três testes realizados a hipótese nula não foi rejeitada, assim, não existem evidências de que o maior ou menor contato com a tecnologia influencia a experiência de fluxo. A hipótese de pesquisa, a experiência de fluxo não apresenta diferença significativa entre os grupos, foi considerada confirmada. Além disso, como a mediana em todos os casos analisados foi igual a cinco, indicando que os participantes experimentaram o fluxo, foram também confirmadas as descrições dos participantes, nas entrevistas e diários, sobre esta experiência.

Assim, os achados sobre a experiência de fluxo da análise qualitativa foram confirmados pela análise quantitativa garantindo uma base mais sólida para a construção da teoria.

\subsection{Construção da teoria}

Tendo como base as relações apresentadas, que foram estabelecidas por meio dos dados, foi elaborado um modelo teórico. Este modelo é exibido na Figura 4.

O modelo teórico serviu de base para a construção da seguinte teoria:

O jogador da terceira idade ao se sentir motivado e gostando de jogar é capaz de experimentar o fluxo com mais facilidade porque ele está mais envolvido com o jogo uma vez que sua concentração está voltada para o mesmo por desejar se divertir, relaxar, superar os desafios e melhorar suas habilidades, e isso faz com que ele perca sua autoconsciência e consequentemente não perceba o tempo passar permitindo lhe sentir prazer suficiente pelo ato de jogar que o impele a se envolver novamente com o jogo.

Assim, o Gostando de jogar e a Motivação são fundamentais para o jogador da terceira idade entrar no estado de fluxo porque eles afetam positivamente elementos desta experiência que são a Percepção de tempo alterada, a Perda da autoconsciência, a Concentração, as Habilidades e a Experiência autotélica.

Estas duas categorias, Gostando de jogar e Motivação, foram consideradas as categorias centrais desta Teoria Fundamentada porque são as mais presentes nas relações desenvolvidas, afetando e sendo afetadas pelas outras categorias.

O efeito positivo do Gostando de jogar também está alinhado com a Teoria da Diversão de Koster [8], porque segundo o autor se divertir é algo fundamental, e nesta pesquisa foi determinado que a Diversão é uma subcategoria de Gostando de jogar, ou seja, uma das razões para o jogador estar gostando de jogar é porque ele está se divertindo.

O Equilíbrio entre desafios e habilidades também é importante para o jogador idoso porque relaciona-se com a Motivação e o Gostando de jogar indicando que a percepção da existência deste equilíbrio é um antecedente significativo para o fluxo. O Equilíbrio entre desafios e habilidades também afeta a Desmotivação comprovando que se o jogador idoso perceber os desafios superiores ou inferiores às suas habilidades este joga pouco ou mesmo desiste do jogo por causa da frustração, tédio e ansiedade.

Revista Brasileira de Computao Aplicada (ISSN 2176-6649), Passo Fundo, v. 9, n. 4, p. 120-135, dez. 2017130 
Figura 4: Modelo teórico

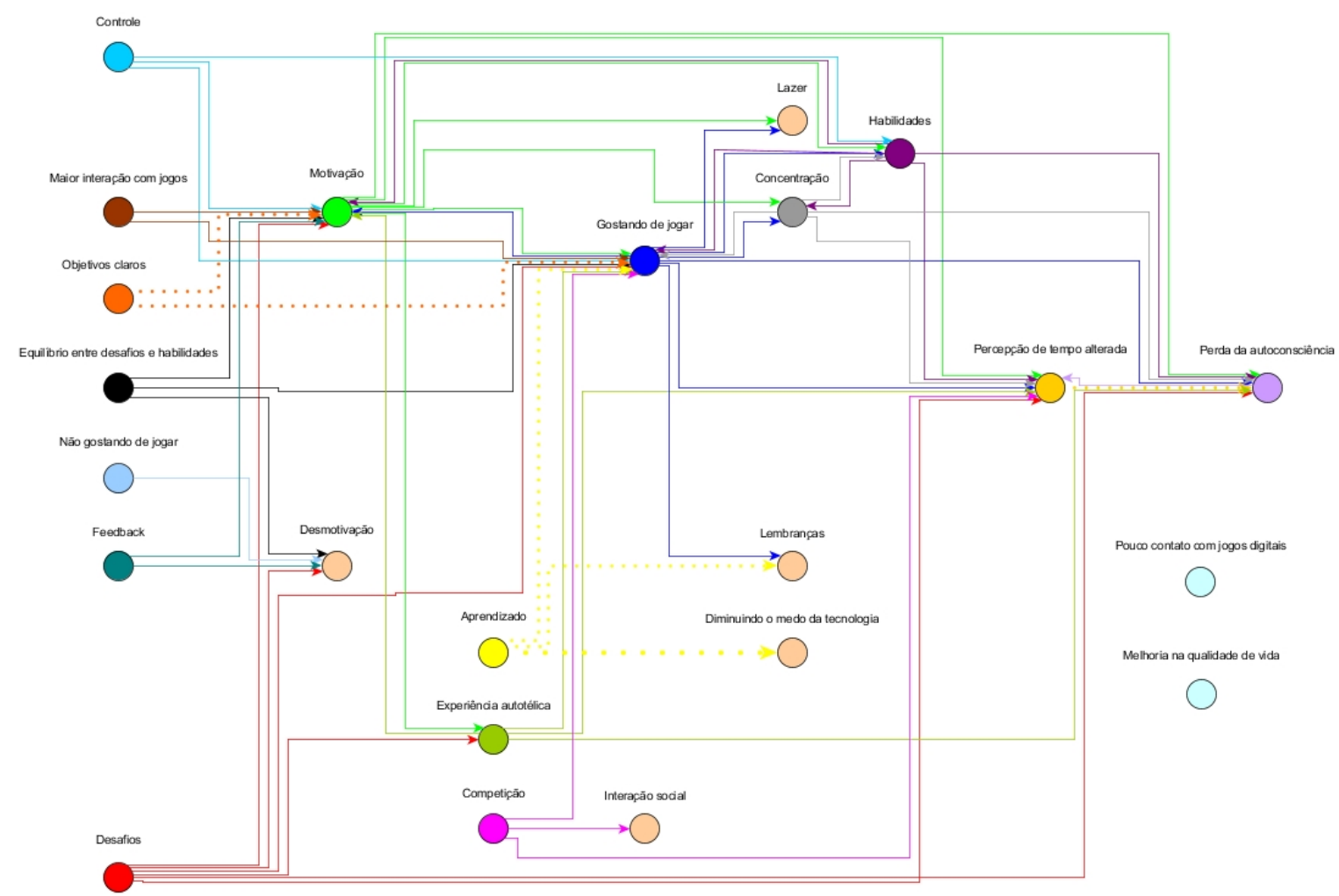

A percepção dos participantes de que o Equilíbrio entre desafios e habilidades são importantes e necessários nos jogos também mostra-se de acordo com Teoria da Diversão porque são formas de evitar a ocorrência do tédio e consequentemente manter o jogador mais envolvido com o jogo.

A satisfação que os participantes sentiram durante o jogo e o desejo de jogarem novamente e de conhecerem novos jogos é o principal indício de que eles experimentaram o fluxo porque segundo Csikszentmihalyi [7], a Experiência autotélica é o objetivo final do estado de fluxo. Assim, ao se envolverem com o jogo ao ponto de sentir prazer e motivação para jogar novamente, os participantes, vivenciaram esta experiência.

$\mathrm{Na}$ Teoria da Diversão, o Aprendizado é um dos elementos fundamentais e os participantes comprovaram este fato ao relatarem que gostaram de aprender e ao se mostrarem interessados em jogos educacionais.

\subsection{Avaliação dos resultados e suas implicações}

Como pode ser observado nas relações apresentadas e na teoria desenvolvida, os elementos do fluxo Concentração, Controle, Desafios, Habilidades, Percepção de tempo alterada, Perda da autoconsciência e Experiência autotélica estão inter-relacionados e, assim, afetam e são afetados mutuamente.

Foi determinado que o Gostando de jogar e a Motivação possuem significativa importância na visão do jogador da terceira idade e, no âmbito desta Teoria Fundamentada, sugere-se que eles devem ser somados aos elementos fundamentais da Teoria do Fluxo de Csikszentmihalyi [7] no contexto de jogos digitais para este público.

A Teoria da Diversão se mostrou aderente aos idosos porque nesta pesquisa os participantes forneceram declarações sobre a relação entre Diversão e Aprendizado e, assim, recomenda-se a utilização desta teoria na criação de jogos voltados para a terceira idade.

É importante ressaltar que independentemente do participante gostar ou não de jogos digitais antes da pesquisa, todos foram capazes de experimentar o fluxo. E aqueles que disseram não gostar, mudaram de opinião e 
sentiram-se inclinados a manter uma relação mais próxima com jogos digitais por causa de vários benefícios que eles perceberam durante este contato.

\section{Considerações finais}

Nesta seção são descritas as considerações finais da pesquisa realizada apresentando uma discussão sobre a validade e as limitações do estudo desenvolvido, descrevendo as conclusões obtidas e sugerindo recomendações para trabalhos futuros.

\subsection{Limitações da pesquisa e ameaças à validade}

Neste trabalho foram utilizados critérios e estratégias para diminuir as ameaças à sua validade e para aumentar a sua qualidade. Os critérios utilizados foram a confiabilidade e a validade interna, e as estratégias foram a triangulação e o método comparativo constante.

Em relação às limitações pode ser dito que apesar das ações tomadas para melhorar o recolhimento de informações nos diários, estas não surtiram o efeito desejado. Alguns dos participantes limitaram-se a anotar apenas a data e o tempo da sessão de jogo e dentre eles apenas dois anotaram estas informações durante as quatro etapas do estudo, sendo os dois do mesmo grupo. A maioria forneceu estas informações com maior regularidade no início, depois passaram a fornecer de forma esporádica ou simplesmente não forneceram. Por esta razão não foi possível fazer uma análise do tempo de jogo dos participantes.

Dessa forma, recomenda-se não utilizar o diário como única fonte de informação porque embora possuam pontos positivos importantes para a coleta de informações, neste trabalho percebeu-se que suas limitações podem ter relevante impacto no estudo realizado.

Outra limitação está relacionada com a abordagem qualitativa: o método de estudo de caso e o número de participantes que não permitem a generalização dos resultados obtidos para a população de idosos. Entretanto, pesquisas qualitativas produzem importantes conhecimentos para o entendimento do fenômeno em estudo, principalmente, quando este é complexo ou não dispõe de informações suficientes na literatura.

\subsection{Conclusões}

Este trabalho teve como objetivo propor estratégias para melhorar a experiência do jogador idoso. A finalidade era possibilitar o desenvolvimento de jogos mais condizentes com os anseios da terceira idade e capazes de atrair mais a sua atenção e interesse.

Visando determinar se o equilíbrio entre os desafios e as habilidades possui importância significativa para o jogador da terceira idade e verificar quais dos outros elementos do fluxo são considerados importantes por ele, uma vez que os resultados encontrados na literatura não foram considerados suficientes, foi realizada uma pesquisa de método misto, na qual foi dado maior enfoque na parte qualitativa. A pesquisa utilizou a abordagem de estudo de caso e em seu planejamento foi definido que seria um estudo de casos múltiplos holístico.

A análise dos dados coletados foi feita utilizando a Teoria Fundamentada para as entrevistas e diários e técnicas estatísticas para a Escala de Fluxo. A Teoria Fundamentada tinha por objetivo propor uma teoria capaz de explicar a importância/não importância do equilíbrio entre os desafios e as habilidades e dos outros elementos do fluxo.

As análises estatísticas foram feitas usando a mediana e o teste de Wilcoxon-Mann-Whitney, uma vez que os dados da Escala de Fluxo são não-paramétricos. O objetivo era realizar a triangulação dos dados e verificar se haveria diferenças significativas no fluxo entre os dois grupos. Os resultados foram considerados satisfatórios para a triangulação e confirmaram a hipótese de que não existiria diferença.

A teoria desenvolvida permitiu a descoberta de dois novos elementos significativos para a experiência de fluxo do jogador da terceira idade: a motivação e o gostando de jogar. Estes elementos estão relacionados positivamente com a experiência autotélica, as habilidades, os desafios, a percepção de tempo alterada, o controle, a

Revista Brasileira de Computao Aplicada (ISSN 2176-6649), Passo Fundo, v. 9, n. 4, p. 120-135, dez. 2017132 
concentração e a perda da autoconsciência. E foram considerados fundamentais para o jogador da terceira idade entrar no estado de fluxo. Estes dois elementos foram as categorias centrais da teoria desenvolvida.

Os resultados da análise qualitativa também indicaram que a Teoria da Diversão é importante para o jogador idoso ao expor a relevância do aprendizado na percepção dos participantes, ao identificar diversas declarações sobre a diversão e ao verificar a relação entre diversão e aprendizado. Assim, recomenda-se a utilização desta teoria na criação de jogos voltados para a terceira idade.

As estratégias identificadas para melhorar a experiência de fluxo do jogador da terceira idade são descritas a seguir:

- Jogos que não oferecem a opção de competição devem ter algum tipo de registro, por exemplo, pontos ou bonificação, que permitam que o jogador busque superar a si mesmo.

- É importante identificar temas e gêneros de jogos que os idosos gostem e que afetem a sua motivação.

- É importante equilibrar desafios e habilidades com foco nos idosos, dada a influência sobre a motivação e o gostar de jogar.

- Jogos devem ser criados de forma a fornecer variações em seus desafios de modo que eles não se tornem repetitivos.

- É importante manter a concentração do jogador uma vez que se relaciona com o gostar de jogar e a motivação.

- É importante prover ao jogador idoso situações de aprendizado devido ao efeito positivo sobre o gostar de jogar e ao interesse demonstrado pelos participantes.

- Os jogos devem auxiliar no combate a doenças cognitivas e na melhoria da qualidade de vida.

Além destas estratégias, é importante que um jogo voltado para a terceira idade atenda características de usabilidade específicas para este público, principalmente, se o jogo for desenvolvido para dispositivos móveis, como smartphones. Estes dispositivos apresentam certas particularidades, como o tamanho da tela reduzido, que podem dificultar o uso por parte dos idosos. Os trabalhos realizados por Santos [17] e Machado [19] podem auxiliar no desenvolvimento de jogos que visam atender a este público-alvo ao discutirem heurísticas de usabilidade e de gameplay voltados para ele.

Outro ponto que deve ser destacado é a necessidade de mais estudos que proponham estratégias para melhoria da experiência do jogador idoso, uma vez que existem poucos estudos sobre este assunto.

Como sugestões adicionais para trabalhos futuros pode-se recomendar: (i) replicar o estudo com outra amostra, criando grupos diferentes, por exemplo, por grau de escolaridade ou por faixa etária e examinar se os achados serão mantidos; (ii) realizar uma pesquisa com enfoque quantitativo em uma amostra maior de idosos para verificar se os resultados deste trabalho serão confirmados; (iii) estudar tipos de desafios adequados para idosos porque segundo os participantes, os desafios são importantes para os jogos digitais e (iiii) desenvolver e avaliar jogos educacionais voltados para o público idoso, uma vez que todos os participantes deste trabalho indicaram ter interesse no aprendizado.

\section{Agradecimentos}

Esta pesquisa recebeu suporte financeiro da PUC Minas, da CAPES e do CNPq (475311/2012-4).

\section{Referências}

[1] UKIE. UK Video Games Fact Sheet. 2015. Disponível em: 〈http://ukie.org.uk/research〉. Acesso em: 7 dez. 2017.

Revista Brasileira de Computao Aplicada (ISSN 2176-6649), Passo Fundo, v. 9, n. 4, p. 120-135, dez. 2017133 
[2] NACKE, L.; LINDLEY, C. A. Flow and immersion in first-person shooters: Measuring the player's gameplay experience. In: CONFERENCE ON FUTURE PLAY: RESEARCH, PLAY, SHARE, 2008. Proceedings... Toronto, Ontario, Canada: ACM, 2008. (Future Play '08), p. 81-88. ISBN 978-1-60558-218-4.

[3] ESA. Essential Facts About the Computer and Video Game Industry. 2007. Disponível em: 〈http://www.org. id.tue.nl/IFIP-TC14/documents/ESA-Essential-Facts-2007.pdf〉. Acesso em: 7 dez. 2017.

[4] ESA. Essential Facts About the Computer and Video Game Industry. 2011. Disponível em: 〈http://www.isfe. eu/sites/isfe.eu/files/attachments/esa_ef_2011.pdf). Acesso em: 7 dez. 2017.

[5] ESA. Essential Facts About the Computer and Video Game Industry. 2014. Disponível em: 〈http://www. theesa.com/wp-content/uploads/2014/10/ESA_EF_2014.pdf $\rangle$. Acesso em: 7 dez. 2017.

[6] UNITED NATIONS. World Population Prospects - The 2015 Revision - Key Findings and Advance Tables. 2015. Disponível em: 〈https://esa.un.org/unpd/wpp/Publications//. Acesso em: 7 dez. 2017.

[7] CSIKSZENTMIHALYI, M. A descoberta do fluxo: a psicologia da vida cotidiana. São Paulo: Rocco, 1999.

[8] KOSTER, R. A Theory of Fun for Game Design. Scottsdale, Arizona: Paraglyph Press, 2004.

[9] MARSTON, H. R. et al. Flow experience of older adults using the istoppfalls exergame. Games and Culture, v. 11, n. 1-2, p. 201-222, 2016.

[10] SOUDERS, D. J. et al. Older adult video game preferences in practice: Investigating the effects of competing or cooperating. Games and Culture, v. 11, n. 1-2, p. 170-200, 2016.

[11] WANG, X. et al. How skill balancing impact the elderly player experience? In: IEEE INTERNATIONAL CONFERENCE ON SIGNAL PROCESSING (ICSP), 13. Proceedings... Chengdu, China, 2016. p. 983-988. ISSN 2164-5221.

[12] LINS, C. et al. Still in flow - long-term usage of an activity motivating app for seniors. In: IEEE INTERNATIONAL CONFERENCE ON E-HEALTH NETWORKING, APPLICATIONS AND SERVICES (HEALTHCOM), 18. Proceedings... Munich, Germany, 2016. p. 1-4.

[13] MERILAMPI, S. et al. The cognitive mobile games for older adults - a chinese user experience study. In: IEEE INTERNATIONAL CONFERENCE ON SERIOUS GAMES AND APPLICATIONS FOR HEALTH (SEGAH), 5. Proceedings... Perth, WA, Australia, 2017. p. 1-6.

[14] KAPPEN, D. L. et al. Design strategies for gamified physical activity applications for older adults. In: HAWAII INTERNATIONAL CONFERENCE ON SYSTEM SCIENCES (HICSS), 49. Proceedings... Koloa, HI, USA, 2016. p. 1309-1318. ISSN 1530-1605.

[15] YIN, R. K. Estudo de Caso: Planejamento e Métodos. 4. ed. Porto Alegre: Bookman, 2010.

[16] CARVALHO, R. N.; ISHITANI, L. Motivational factors for mobile serious games for elderly users. In: SBGAMES, 11. Proceedings... Brasília, Brasil: SBGames, 2012.

[17] SANTOS, L. G. Uma Proposta de Heurísticas para Avaliação de Usabilidade de Jogos Casuais para Dispositivos Móveis Voltados para Idosos. Tese (Mestrado em Informática) — Pontíficia Universidade Católica de Minas Gerais, Belo Horizonte, 2014.

[18] COTA, T. T. Projeto de Jogos Móveis para Idosos: Um estudo com foco na motivação para jogar. Tese (Mestrado em Informática) — Pontíficia Universidade Católica de Minas Gerais, Belo Horizonte, 2014.

[19] MACHADO, M. C. Uma Proposta de Heurísticas para Avaliação de Gameplay Direcionadas a Adultos mais Velhos. Tese (Mestrado em Informática) - Pontíficia Universidade Católica de Minas Gerais, Belo Horizonte, 2015.

[20] SILVA, R. S. et al. Viajando pelo mundo: um projeto de jogo para smartphone com foco em idosos. In: SBGAMES, 13. Proceedings... Porto Alegre, Brasil: SBGames, 2014.

Revista Brasileira de Computao Aplicada (ISSN 2176-6649), Passo Fundo, v. 9, n. 4, p. 120-135, dez. 2017134 
[21] FOLSTEIN, M. F.; FOLSTEIN, S. E.; MCHUGH, P. R. "Mini-mental state": A practical method for grading the cognitive state of patients for the clinician. Journal of Psychiatric Research, v. 12, n. 3, p. 189 - 198 , 1975. ISSN 0022-3956.

[22] SINGH, A.; MALHOTRA, S. A researcher's guide to running diary studies. In: ASIA PACIFIC CONFERENCE ON COMPUTER HUMAN INTERACTION, 11. Proceedings... Bangalore, India: ACM, 2013. (APCHI '13), p. 296-300. ISBN 978-1-4503-2253-9.

[23] NEWZOO. Global Games Market Report. 2017. Disponível em: 〈http://resources.newzoo.com/ global-games-market-report-light-2017〉. Acesso em: 7 dez. 2017.

[24] FLICK, U. Introdução à Pesquisa Qualitativa. 3. ed. Porto Alegre: Artmed, 2009.

[25] CRESWELL, J. W. Projeto de Pesquisa. 2. ed. Porto Alegre: Artmed, 2007.

[26] KIILI, K.; LAINEMA, T. Foundation for measuring engagement in educational games. Journal of Interactive Learning Research, Association for the Advancement of Computing in Education (AACE), Chesapeake, VA, v. 19, n. 3, p. 469-488, July 2008. ISSN 1093-023X.

[27] MEKLER, E. D. et al. A diary study exploring game completion and player experience. In: ACM SIGCHI ANNUAL SYMPOSIUM ON COMPUTER-HUMAN INTERACTION IN PLAY, 1. Proceedings... Toronto, Ontario, Canada: ACM, 2014. (CHI PLAY'14), p. 433-434. ISBN 978-1-4503-3014-5.

[28] DEARMAN, D.; KELLAR, M.; TRUONG, K. N. An examination of daily information needs and sharing opportunities. In: ACM CONFERENCE ON COMPUTER SUPPORTED COOPERATIVE WORK, 2008. Proceedings... San Diego, CA, USA: ACM, 2008. (CSCW '08), p. 679-688. ISBN 978-1-60558-007-4.

[29] KIILI, K. et al. The design principles for flow experience in educational games. Procedia Computer Science, v. 15 , n. 0 , p. $78-91,2012$. ISSN 1877-0509.

[30] KARA, N.; CAGILTAY, K. Flow experiences of adolescents in terms of internet café environment and computer game play characteristics. Procedia - Social and Behavioral Sciences, v. 89, n. 0, p. 298 - 307, 2013. ISSN 1877-0428. 2nd Cyprus International Conference on Educational Research (CY-ICER 2013).

[31] KIILI, K. et al. Flow framework for analyzing the quality of educational games. Entertainment Computing, v. 5, n. 4, p. 367 - 377, 2014. ISSN 1875-9521.

[32] BRYMAN, A. Quantitative and qualitative research: further reflections on their integration. In: BRANNEN, J. (Ed.). Mixing methods: Qualitative and quantitative research. Aldershot: Avebury, 1992. p. 57-78.

[33] CHARMAZ, K. A construção da teoria fundamentada: guia prático para análise qualitativa. Porto Alegre: Artmed, 2009.

[34] WITTE, R. S.; WITTE, J. S. Estatística. 7. ed. Rio de Janeiro: LTC Editora, 2005.

[35] GLASER, B.; STRAUSS, A. The Discovery of Grounded Theory: Strategies for Qualitative Research. Chicago: Aldine Transaction, 1967.

[36] R Core Team. R: A Language and Environment for Statistical Computing. Vienna, Austria, 2015. Disponível em: 〈http://www.R-project.org/〉. Acesso em: 7 dez. 2017.

[37] VIALI, L. Testes de Hipóteses Não Paramétricos. 2008. Apostila - UFRGS. Disponível em: 〈http://www. mat.ufrgs.br/ viali/estatistica/mat2282/material/apostilas/Testes_Nao_Parametricos.pdf $\rangle$. Acesso em: $7 \mathrm{dez}$. 2017. 